\title{
Knowledge of caretakers about routine immunization and reasons for partial immunization in rural areas of Jamnagar District
}

Background: Routine immunization (RI) is one of the most cost-effective public health interventions, first introduced in India in 1978. Yet, despite the concerted efforts of the government and other health agencies, a large proportion of vulnerable infants and children in India remain unimmunized. Objectives: Objective of this study was to know about perception of caretakers of beneficiaries about RI in terms of knowledge about vaccines and vaccine preventable diseases and reasons for missed opportunity of immunization. Materials and Methods: Community based cross-sectional study was conducted during January-June 2012 in a rural area of Jamnagar district. A total of 200 children aged 12-24 months were selected using stratified random sampling method. Results: Nearly $52 \%$ children were fully immunized. Most common reasons for partially immunization were sick child $(68.9 \%)$ followed by vaccine not available $(32.3 \%)$ and being outside on the day of session (31.11\%). Nearly $61 \%$ Guardians knew about Polio vaccine, main source of information about RI was health worker (83.5\%). There was statistical significant association between education of mother and immunization status of children. Conclusion: There is a need to strengthen Information Education Communication activities to improve knowledge regarding immunization among people, motivation of health workers to disseminate information regarding immunization. Hence, that immunization coverage should be improved.

Key words: Immunization, knowledge, vaccine, vaccine preventable diseases

Sonal M. Dindod, Naresh R. Makwana, Sudha B. Yadav

Department of Community Medicine, Shri M. P. Shah Government Medical College,

Jamnagar, Gujarat, India

Address for the Correspondence:

Dr. Sonal M. Dindod, Department of Community Medicine, Shri M. P. Shah Government Medical College, Jamnagar, Gujarat, India. E-mail: sonald25@gmail.com

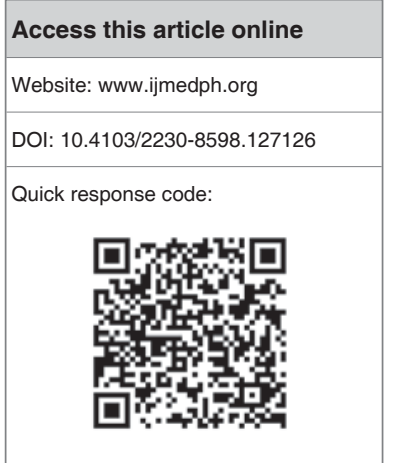

\section{INTRODUCTION}

The Expanded Program on Immunization (EPI) was initiated by Government of India in 1978 with the objective of reducing morbidity, mortality and disabilities from these six diseases by making free vaccination services easily available to all eligible children. The Universal Immunization Program (UIP) was introduced in 1985-86..$^{[1]}$ Routine immunization (RI) services are provided on village health and nutrition day (VHND), which is also known as Mamta Diwas in Gujarat. The VHND is to be organized every Monday at Primary Health Center (PHC) and once in every month (mostly on Wednesday) at the Anganwadi center/sub-center (SC) in the village.

All vaccines under RI are provided free of charge. However, figures for RI coverage are lagging. Hence, what could be possible reasons that hamper progress? ${ }^{[2]}$ Keeping the above fact in mind present study was conducted with the objective to know about perception of caretakers of beneficiaries about RI in terms of knowledge about vaccines and vaccine preventable diseases and to explore reasons for missed opportunity of immunization.

\section{MATERIALS AND METHODS}

The ethical clearance from the Institutional Ethical Committee was obtained before conducting the study.

A community based cross-sectional study was carried out in a rural area of the study district, from January to June 2012. Study units were taken according to multistage sampling method. ${ }^{[3]}$ The study district has 10 Talukas. For the purpose of study, one PHC from each taluka and two SCs (one good 
performing and one poor performing) from the selected $\mathrm{PHC}$ were taken. Thus, total 30 centers (10 PHCs and 20 SCs) were identified for the study.

For the perception of beneficiaries regarding Immunization, ten care-takers from PHC and five care-takers, from each SC, of children aged 12-23 months attending Mamta day were interviewed by using purposive random sampling method, using pre-tested, pre-designed Performa. Thus, making a total of 200 were respondents and all the study individuals were clearly explained the purpose of study and their verbal consent was taken before filling up the performa. All the individuals who participated in the study gave their consent to be part of the study and the response rate was 100\%.

\section{Statistical study}

Data entry and analysis were performed in Microsoft Office 2007-excel. Appropriate statistical test, such as Chi-square test, was applied, wherever required.

\section{Definitions used in the study}

1. Fully immunized: The child was considered fully immunized if he/she received one dose each of bacillie-calmette-guerin (BCG) and measles and three doses of diphtheria-pertusisTetanus (DPT), hepatitis-B and oral polio (apart from zero dose of oral polio at birth) by his/her $1^{\text {st }}$ birthday.

2. Partially immunized: Those who had missed even one vaccine out of the primary vaccines. ${ }^{[4,5]}$

\section{RESULTS}

Out of total 200 children studied $52 \%$ children were fully immunized and $48 \%$ children were partially immunized as shown in Figure 1.
Findings in Table 1 shows $56.5 \%$ children were male, $80.5 \%$ children were Hindu, $87 \%$ deliveries were institutional, $64 \%$ children were of $\leq 2^{\text {nd }}$ birth order and $28 \%$ mothers were illiterate. There was statistically significant association between immunization status of children and religion, birth order and education of mother.

Knowledge of caretakers of beneficiaries about RI is shown in Table 2. Nearly 45\% parents/guardian correctly knew day for RI i.e., on Mamta day in their village (Monday at PHC and Wednesday at SC). About $67.2 \%$ parents/guardian did not correctly know up to which age vaccines of RI can be given. Furthermore, only $23.55 \%$ of parents/guardians can give the name of at least 3 vaccine preventable diseases covered under RI.

Figure 2 shows main source of information about RI. 83.5\% respondents told that health workers (female health worker (FHW), Anganwadi worker (AWW) were the main source of information. Doctors and family members were another source of information, but in limited numbers.

As shown in Table 3, majority parents/guardians i.e., 61.5\% knew about polio, followed by $40 \%$ about measles and $30.5 \%$ about BCG.

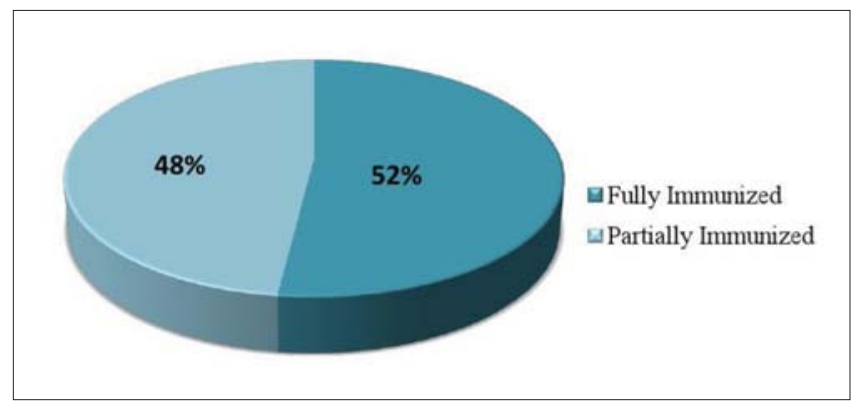

Figure 1: Immunization status of children $(n=200)$

\begin{tabular}{|c|c|c|c|c|c|}
\hline \multirow{2}{*}{$\begin{array}{l}\text { Demographic } \\
\text { characteristics }\end{array}$} & \multicolumn{2}{|c|}{ Immunization status } & \multirow[t]{2}{*}{ Total (\%) } & \multirow[t]{2}{*}{$\chi^{2}$ value } & \multirow[t]{2}{*}{$P$ value } \\
\hline & Fully immunized (\%) & Partially immunized (\%) & & & \\
\hline \multicolumn{6}{|l|}{ Sex } \\
\hline Male & $64(56.6)$ & $49(43.4)$ & $113(56.5)$ & 2.238 & 0.13 \\
\hline Female & $40(46.6)$ & $47(54)$ & $87(43.5)$ & & \\
\hline \multicolumn{6}{|l|}{ Religion } \\
\hline Hindu & $91(56.5)$ & $70(43.5)$ & $161(80.5)$ & 6.763 & 0.009 \\
\hline Muslim & $13(33.3)$ & $26(66.75)$ & $39(19.5)$ & & \\
\hline \multicolumn{6}{|l|}{ Place of delivery } \\
\hline Institutional delivery & $93(53.4)$ & $81(46.6)$ & $174(87)$ & 1.232 & 0.54 \\
\hline By trained personnel & $8(44.4)$ & $10(55.65)$ & $18(9)$ & & \\
\hline By un trained personnel & $3(37.5)$ & $5(62.5)$ & $8(4)$ & & \\
\hline \multicolumn{6}{|l|}{ Birth order } \\
\hline$\leq 2$ & $78(60.93)$ & $50(39.06)$ & $128(64)$ & 0.0006 & 0.001 \\
\hline $3^{\text {rd }}$ and above & $26(36.11)$ & $46(63.9)$ & $72(36)$ & & \\
\hline \multicolumn{6}{|l|}{ Mother's education } \\
\hline Illiterate & $16(28.6)$ & $40(71.4)$ & $56(28)$ & 19.398 & 0.001 \\
\hline Primary & $58(58)$ & $42(42)$ & $100(50)$ & & \\
\hline Secondary & $24(64.9)$ & $13(35.1)$ & $37(18.5)$ & & \\
\hline Higher secondary & $6(85.7)$ & $1(14.35)$ & 7 (3.5) & & \\
\hline
\end{tabular}


Other findings of the table were that $15 \%$ respondents knew about hepatitis-B, only $4 \%$ about DPT.

Figure 3 indicates 68.95 respondents told that child was sick on the day of immunization. Almost one-third (32.3\%) went for the immunization on the day of RI, but the vaccine was not available and $31.11 \%$ went outside on the day of the session.

\section{DISCUSSION}

In a present study, $52 \%$ children were fully immunized, which is similar with a study conducted by Joshi et al. ${ }^{[6]}$ where $50 \%$ children were fully immunized. Findings of the current study is in between data of NFHS-III, which shows $40.1 \%$ children in rural area and coverage evaluation survey $2009^{[7]}$ shows $56.6 \%$ children were fully immunized.

Out of the 200 children, $56.5 \%$ were males and $43.5 \%$ were females, which have similar findings with study of Manjunath and Pareek ${ }^{[8]}$ (59\% were male children). There was no statistically significant association between sex of children and immunization status of children, but fully immunized children were predominantly male. The female children were less likely to receive complete immunization and more likely to remain partially immunized. This shows neglect

\section{Table 2: Knowledge about RI}

\begin{tabular}{lc} 
Knowledge about RI & Frequency $(\mathbf{n}=\mathbf{2 0 0})(\%)$ \\
\hline Having correct knowledge of day of RI & $90(45)$ \\
Having correct knowledge about age & $65(32.5)$ \\
up-to which RI is given & \\
Can give name of at least 3 VPDs & $47(23.5)$ \\
\hline
\end{tabular}

$\mathrm{RI}=$ Routine immunization, $\mathrm{VPD}=$ Vaccine preventable diseases

\begin{tabular}{lc}
$\begin{array}{l}\text { Table } 3: \text { Knowledge about name of vaccines to be } \\
\text { given on the day of RI }\end{array}$ \\
\hline Name of vaccines & Frequency (\%) \\
\hline BCG & $61(30.5)$ \\
Polio & $123(61.5)$ \\
DPT & $8(4)$ \\
Hep B & $30(15)$ \\
Measles & $80(40)$ \\
\hline
\end{tabular}

BCG = Bacillie calmette guerin, DPT = Diphtheria-pertusis-tetanus, $\mathrm{RI}=$ Routine immunization

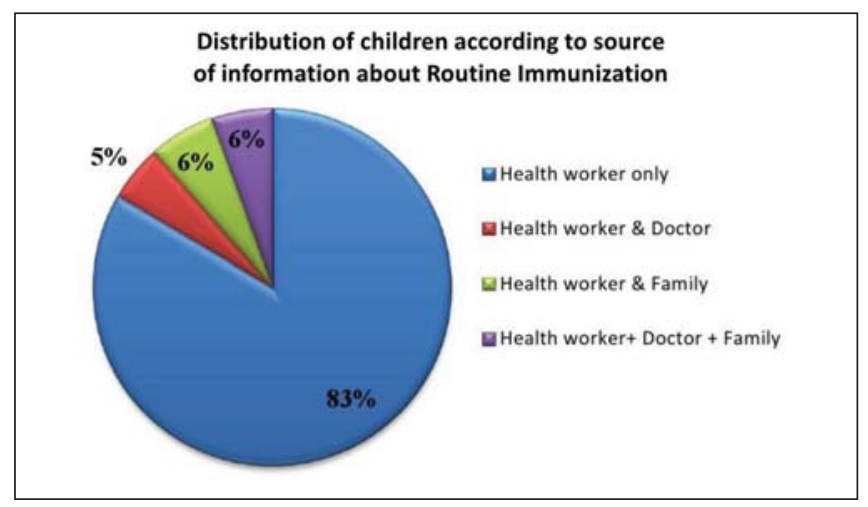

Figure 2: Source of information about routine immunization of caretakers about immunization of female children. These findings were also supported by the findings of the study conducted by Yadav and Singh. ${ }^{[9]}$ In a study $87 \%$ deliveries were Institutional, whereas $13 \%$ were Home deliveries. Study of $\mathrm{Nath}^{[5]}$ shows that $50 \%$ deliveries were institutional which is quite lower than the present study. Present study shows that out of total deliveries $9 \%$ home deliveries were conducted by trained personnel and $4 \%$ by untrained personnel, in contrast $\mathrm{Nath}^{[5]}$ found that $23.9 \%$ were home delivery by trained personnel and $26.1 \%$ were home deliveries by un-trained personnel. In the present study, institutional deliveries were high, also home deliveries by trained personnel were high. This might due to awareness and motivation of people regarding institutional deliveries in a study district. There was no association between place of delivery and immunization status of children. However, more numbers of children who delivered institutionally were fully immunized. Whereas in a study conducted by Kumar ${ }^{[4]}$ shows that deliveries in the hospital, including those born by cesarean section, were more likely to be fully immunized $(P<0.001)$. This may be because vaccination was started at birth and parents were educated regarding subsequent vaccinations. Therefore, institutional deliveries should be promoted to increase the coverage of immunization. As shown in Table 1, 64\% children were $\leq 2^{\text {nd }}$ order birth, which was quite higher than studies conducted by $\operatorname{Kumar}^{[4]}$ where $54.15 \%$ children were $\leq 2^{\text {nd }}$ birth order and $\mathrm{Nath}^{[5]}$ where $56.9 \%$ children were $\leq 2^{\text {nd }}$ order birth. There was a significant association between birth order and immunization status of children. More number of children of birth order $\leq 2$ were fully immunized, whereas children of birth order $3^{\text {rd }}$ and above were more likely to remain partially immunized. In a present study, $80.5 \%$ children were Hindus while $19.5 \%$ were Muslims. Similar findings were found in studies of Yadav and Singh, ${ }^{[9]}$ Rachna and Vyas, ${ }^{[10]}$ Nath.${ }^{[5]}$ Statistical significant association was observed between religion and immunization status of children. Low coverage of complete immunization among Muslim children has been observed by other authors Kumar, ${ }^{[4]}$ Nath et al. ${ }^{[11]}$ Yadav and Singh..$^{[9]}$ As shown in Table 1, 28\% mothers were illiterate which is little more than study of Rachna and Vyas ${ }^{[10]}$ where $22 \%$ mothers were illiterate. There was statistical significant association between education of mother and immunization status of children. As literacy status increases, more number of children was fully immunized. This might due to increase awareness about RI.

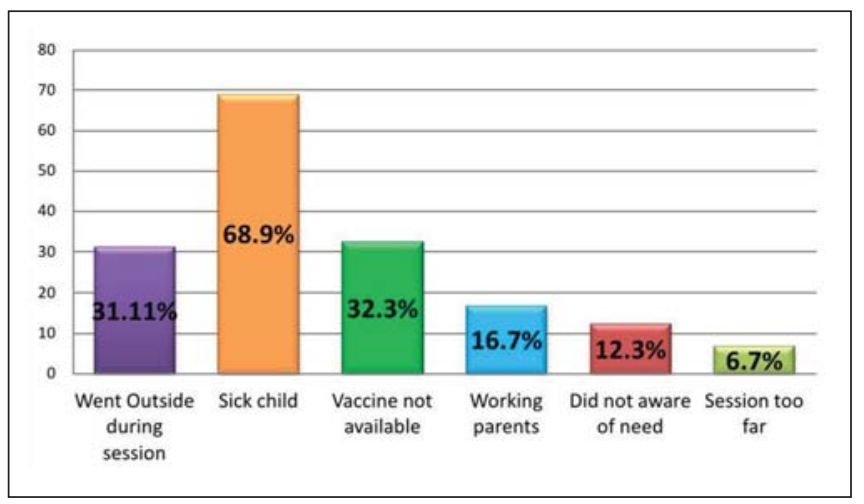

Figure 3: Reasons for partial immunization 
Literacy status of mothers is a key determinant of access to health services as well as utilization of child health services.

Table 2 shows that $45 \%$ parents/guardian correctly knew day for RI i.e., on Mamta day in their village (Monday at PHC and Wednesday at SC), which is little higher than a study conducted by Sharma and Bhasin ${ }^{[2]}$ where $37 \%$ respondents knew correctly day of $\mathrm{RI}$ in the week. About $67.2 \%$ parents/guardian did not correctly know up to which age vaccines of RI can be given, which is quite higher than study of Sharma and Bhasin ${ }^{[2]}$ where $50.9 \%$ respondents did not correctly know the age group for RI. Furthermore, only $23.55 \%$ parents/guardians can give the name of at least 3 vaccine preventable diseases covered under RI, whereas in a study of Nisar et al. ${ }^{[12]}$ about $54 \%$ of women reported exact number of diseases against, which EPI is scheduled. This shows poor knowledge of caretakers of beneficiaries regarding RI.

Main source of information was health worker (FHW, AWW) alone in $83.5 \%$ cases as indicated in Figure 2 . This was because the majority of the respondents had availed the services at PHCs and SCs and these health functionaries seem to be most readily available and accessible to people. These findings were similar with the findings of Rachna and Vyas, ${ }^{[10]}$ Nath, ${ }^{[5]}$ Abdulraheem et al., ${ }^{[13]}$ Nisar et al. ${ }^{[12]}$ Family and Doctors were considerably lower as the source of information about RI. Furthermore, present study shows that people did not get information from television, radio or media. Hence, to increase awareness media i.e., television, radio and newspapers should be more utilized.

Table 3 suggests that $61.5 \%$ respondents knew about Polio, followed by $40 \%$ about Measles and $30.5 \%$ about BCG. In a study of Nisar et al. ${ }^{[12]} 75.6 \%$ mentioned polio vaccine, $40.4 \%$ tuberculosis, $33.5 \%$ measles In a study of Rachna and Vyas, ${ }^{[10]} 85 \%$ knew about Poliomyelitis while measles and Tuberculosis was known to 40-35\% of respondents, while in the study conducted by Sharma and Bhasin ${ }^{[2]}$ maximum number of respondents i.e., $61 \%$ knew about measles followed by tuberculosis $52.5 \%$. These findings show that a majority of respondents knew about Polio followed by measles and BCG. It may be due to intensive Information Education Communication (IEC) activities done for intensified pulse polio immunization and oral polio vaccine is given as drops. Hence, people can easily identify this vaccine and disease. This could be attributed to the fact that the parents are more concerned about the health of the newborn child and since BCG is the first vaccine to be administered, most of them get their child immunized with the vaccine and if not, they at least acquire knowledge about immunization. Only 15\% respondents knew about hepatitis-B and $4 \%$ about DPT. This could be attributed to the triple dose schedule of DPT, which makes it difficult for people to remember the schedule. The confusion is also compounded by the administration of hepatitis- $\mathrm{B}$, which is given on the same day but on a different site.

As shown in Figure 3, most common reasons for partial immunization were sick child $(68.9 \%)$ followed by Vaccine not available (32.3\%) and caretakers went outside on the day of session
(31.11\%). These findings were similar to study of Manjunath and Pareek. ${ }^{[8]}$ These findings suggest that there was misconception regarding immunization during minor illness, which requires education of people regarding RI.

\section{LIMITATIONS}

The respondents comprised of caretakers who brought their children to the centers for immunization and the result would not be generalizable to the whole population. It may be presumed that the knowledge and motivation levels regarding RI would be low among those who did not turn up and thus the actual figures for the community as a whole can be expected to be lower than the study's findings.

\section{CONCLUSION}

Based on these limitations, it can conclude that there was unsatisfactory knowledge about the UIP. Respondents' inability to name or identify diseases other than poliomyelitis and tuberculosis indicate that health education activities should be emphasized to enhance respondents' knowledge about the immunization program. The fact that minor illnesses, such as cough and diarrhea, are not a contra-indication to vaccination needs to be told to the parents.

Also gaps regarding the knowledge about correct age of vaccine administration, doses and place of vaccination should be filled along with the improvement in the literacy status of the mothers/ guardian. This would require appropriate information dissemination, aggressive campaigning and family involvement as crucial to the success of the program. At the grass root level, mass media and other means of IEC activities should be harnessed to the maximum extent so as to increase the knowledge and change the attitude regarding immunization among people.

\section{REFERENCES}

1. National Family Health Survey-3 (NFHS III) 2005-2006. Mumbai: Ministry of Health and Family Welfare, Government of India, International Institute of Population Sciences; 2007.

2. Sharma R, Bhasin SK. Routine immunization-do people know about it? A study among caretakers of children attending pulse polio immunization in East Delhi. Indian J Community Med 2008;33:31-4.

3. Mahajan BK. Methods in Biostatistics: For Medical Students and Research Workers. $7^{\text {th }}$ ed. New Delhi: Jaypee Brothers Medical Publishers (P) Ltd; 2010. p. 90

4. Kumar D, Aggarwal A, Gomber S. Immunization status of children admitted to a tertiary-care hospital of north India: Reasons for partial immunization or non-immunization. J Health Popul Nutr 2010;28:300-4.

5. Nath B, Singh JV, Awasthi S, Bhushan V, Kumar V, Singh SK. KAP study on immunization of children in a city of North India - A 30 cluster survey. Online J Health Allied Sci 2008;7:2.

6. Joshi HS, Gupta R, Singh A, Mahajan V. Assessment of immunization status of children between 12-23 months in Bareilly District. Nepal J Epidemiol 2011;1:47-50.

7. 2009 Coverage Evaluation Survey. All India report. New Delhi: Unicef. Available from: http://www.unfpa.org/sowmy/resources/docs/library/ R309_UNICEF_2010_INDIA_2009CoverageSurvey.pdf. [Last accessed on 2012 May 15]. 
8. Manjunath U, Pareek RP. Maternal knowledge and perceptions aboutthe routine immunization programme - A study in a semiurban area in Rajasthan. Indian J Med Sci 2003;57:158-63.

9. Yadav RJ, Singh P. Immunization status of children and mother in the state of Madhya Pradesh. Indian J Community Med 2004;29:147-8.

10. Rachna K, Vyas S. Awareness and knowledge of mothers of under five children regarding mmunization in Ahmedabad. Healthline 2010;1:16-8

11. Nath B, Singh JV, Awasthi S, Bhushan V, Kumar V, Singh SK. A study on determinants of immunization coverage among 12-23 months old children in urban slums of Lucknow district, India. Indian J Med Sci 2007;61:598-606.

12. Nisar N, Mirza M, Qadri MH. Knowledge, attitude and practices of mothers regarding immunization of one year old child at Mawatch Goth, Kemari Town, Karachi. Pak J Med Sci 2010;26:183-6.

13. Abdulraheem IS, Onajole AT, Jimoh AA, Oladipo AR. Reasons for incomplete vaccination and factors for missed opportunities among rural Nigerian children. J Public Health Epidemiol 2011;3:194-203.

How to cite this article: Dindod SM, Makwana NR, Yadav SB. Knowledge of caretakers about routine immunization and reasons for partial immunization in rural areas of Jamnagar District. Int J Med Public Health 2014;4:57-61.

Source of Support: Nil, Conflict of Interest: None declared. 